\title{
Dangerous severe personality disorder
}

\section{Adrian Feeney}

Abstract The Draft Mental Health Bill was published in June 2002 and was widely criticised. There were particular
concerns regarding the possible detention of those with personality disorders solely for the protection
of the general public. Subsequently the Draft Bill was omitted from the Queen's speech in November
2002. The Department of Health has stated that it intends to push for the Bill's inclusion in the next
Parliamentary year. This review attempts to summarise the present situation so as to inform the
debate. It considers the relationship between personality disorder and risk, with examination of
treatment models and the existing and proposed mental health legislation.

'... there is, however, a group of dangerous and severely personality disordered individuals from whom the public at present are not properly protected ... there should be new legislative powers for the indeterminate, but renewable detention of dangerously personality disordered individuals. These powers will apply whether or not someone was before the courts for an offence.'

The Home Secretary Jack Straw,

House of Commons, February 1999 (Straw, 1999)

The White Paper Reforming the Mental Health Act. Part II: High Risk Patients (hereafter referred to as the White Paper) identified these individuals as dangerous and severely personality disordered (DSPD) (Department of Health, 2000). This phrase has been attacked as 'a neologism that has no legal or medical status' (Farnham \& James, 2001). However, DSPD is not mentioned in the Draft Mental Health Bill and this may be as a result of such criticism. Despite this, the draft Bill does have the scope to detain 'those who pose a substantial risk of harm to others' (Department of Health, 2002: Clause 6(4)).

\section{The problem}

The issue of how to protect society from those who are violent and/or commit sexual offences is both topical and highly controversial. It gained public attention with the first conviction of Michael Stone for the murder of Lin and Megan Russell in 1998. More recently, in December 2001, the conviction of Roy Whiting for the murder of Sarah Payne rekindled the debate. In December 2001, the Lord Chief
Justice Lord Woolf suggested on Radio 4's The Today Programme that there should be a form of protective custody for 'a very small minority of people' in order to protect the public (Rozenberg, 2001). Lord Woolf stated that he recognised that this was a great infringement on the rights of the individual, but he argued that this had to be weighed against the rights of those who would be offended against in the future. The Government too shares the belief that there is a small group of individuals who pose a risk to society because of their severe personality disorder. It has been estimated that, at the end of July 1997, there were about 1400 male prisoners, 400 male patients in special hospitals and between 300 and 600 people in the community who required protective custody (Singleton et al, 1998). The Government is concerned that a single group of high-risk individuals are responsible for a disproportionate number of violent and sexual crimes. It has been estimated that about 30 prisoners are released every month whose history causes significant concern regarding risk of future serious violent or sexual crime.

\section{The link between violence and personality disorder}

There is an extensive history of attempts to categorise those whose violent behaviour appears to be linked to their inherent make up in the absence of disorders of intellect or perception. As early as the beginning of the 19th century Pinel distinguished between mental illness and such inherent characteristics (manie sans delire) in order to aid the courts. Prichard (1835) outlined moral insanity in 1835 and described

Adrian Feeney is a specialist registrar on the South West forensic rotation, presently working at Fromeside Clinic (Blackberry Hill Hospital, Manor Road, Fishponds, Bristol BS16 2EW, UK. Tel: 0117958 3678; fax: 01179585477 ; e-mail: Adrian.Feeney@awp.nhs.uk). His clinical interests include mental health law and substance misuse. 


\section{Box 1 Moral insanity}

In 1835, Pritchard lsited the ofllowing as characteristics of moral insanity

- Moral derangement (emotional or psychological)

- Loss of self-control

- Abnormal temper, emotions and habits

- Abnormal inclinations, likings and attachments

- Normal 'intellect'

- Rational but incapable of decency

- No delusions or hallucinations

a condition which is the recognisable forerunner of the modern concept of dissocial personality disorder (Box 1).

The place of personality disorder as poor relation of mental illness was propagated by Koch's construct of psychopathic inferiority, which he described as a constitutional degeneration. More recently, Cleckley described psychopathy. In his book The Mask of Sanity, he theorised that those who suffer from psychopathy appear sane but have profoundly disordered thinking (Cleckley, 1941). He outlined the syndrome of psychopathy and described its abnormalities in interpersonal, affective and behavioural symptoms (Box 2). However, Lewis (1974) has criticised such attempts to categorise abnormal personality as 'disheartening ... and characterised by therapeutic gloom'.

Hare, working with male offenders and forensic inmates in Canada, attempted to identify the most diagnostically useful of these features and to

\author{
1941) \\ Interpersonal \\ Superficially charming \\ Grandiose \\ Egocentric \\ Manipulative \\ Affective \\ Shallow, labile emotions \\ Lack of empathy \\ Lack of guilt \\ Little subjective distress \\ Behavioural \\ Impulsive \\ Irresponsible \\ Prone to boredom \\ Lack of long-term goals \\ Prone to breaking rules
}

Box 2 Features of psychopathy (Cleckley, operationalise them into a standardised tool, the Psychopathy Checklist (PCL), which was later revised (PCL-R) (Hare, 1991). The PCL-R rates clinical notes and informants with or without interview on 20 features of psychopathy, which are rated on a three-point scale $(0,1$ or 2$)$, giving a maximum possible score of 40 . Hare emphasises that the PCL-R was originally designed to identify psychopathy rather than as a risk assessment tool. However, Hare has published data to show that those with PCL-R scores greater than 30 had significantly higher rates of recidivism (Hare et al, 2000). It has also been shown that this group had adverse treatment outcomes (Rice et al, 1992).

The closest clinical constructs to that of psychopathy in the two major diagnostic systems are 'dissocial personality disorder' in ICD-10 (World Health Organization, 1992) and 'antisocial personality disorder' in DSM-IV (American Psychiatric Association, 1994). The DSM-IV has arranged the personality disorders into three clusters, on the basis of empirical observation (Table 1). Of those who fulfil personality disorder criteria, those in cluster $\mathrm{B}$ are likely to be most disruptive.

Hare recognises that antisocial personality disorder is related to psychopathy, but states that it places greater emphasis on early-onset delinquency (based on Robbins' work) and lacks an operationalised diagnostic tool (Robbins, 1966; Hare et al, 2000). It has been noted that psychopathy is a relatively rare condition and that there is therefore a greater chance of false positives rather than false negatives when screening for it. There is a potential spurious association between high scores on the PCL-R and previous offending behaviour since the PCL-R rates a variety of offending behaviours.

Seventy-eight per cent of male remand prisoners, $64 \%$ of sentenced male and $50 \%$ of female prisoners in one survey of penal institutions in England and Wales were shown to fulfil the criteria for personality disorder (Singleton et al, 1998). These inmates were

\section{Table 1 DSM-IV classification of personality} disorders

$\begin{array}{lll}\text { Cluster } & \text { Description } & \text { Disorder } \\ \text { A } & \text { Odd or eccentric } & \text { Paranoid } \\ \text { behaviour } & \text { Schizoid } \\ & \text { Schizotypal } \\ \text { B } & \text { Dramatic or emotional } & \text { Antisocial } \\ & \text { behaviour } & \text { Borderline } \\ & & \text { Histrionic } \\ & & \text { Narcissistic } \\ \text { C } & \text { Anxious or avoidant } & \text { Avoidant } \\ & \text { behaviour } & \text { Dependent } \\ & & \text { Obsessive- } \\ & & \text { compulsive }\end{array}$


also more likely to have previously supported themselves financially by crime. There is, however, some circularity in diagnosing dissocial personality (which includes disregard for social rules and norms) and previous criminal behaviour in the same individual.

\section{Culpability and personality disorders}

Hare stated that psychopaths know the rules of the game, i.e. right from wrong, and should not be dealt with as though they are ill (Hare et al, 1999). A report for the Department of Health \& Home Office (1994), on the other hand, argued that those suffering from psychopathic disorder are unaware that their actions are wrong and therefore should not be blamed for them. Such debate dates back well over 100 years and has led to the creation of a series of categories: moral imbecility (Mental Deficiency Act 1913), moral defect (Mental Deficiency Act 1927) and psychopathic disorder (Mental Health Acts 1959 and 1983).

\section{Treatability and personality disorders}

Ambivalence towards patients diagnosed with personality disorder is well recognised among psychiatrists (Lewis \& Appleby, 1988). Nonengagement with these patients on the grounds of the treatability clause within the Mental Health Act 1983 has been commonplace. Such selection for admission of only those deemed to be treatable reenforces the impression voiced by Jack Straw that psychiatrists are 'writing off' the remainder (Straw, 1999). Gunn (2000) commented that it is unfortunate that when psychiatrists reject such individuals, they often become the responsibility of the criminal justice system, which is ill-equipped to help them.

\section{Legislation in England and Wales}

There are a number of options already available to the courts that allow for prolonged detention in order to protect the public. A conviction of murder results in a mandatory life sentence, and discretionary life sentences are available for crimes that are deemed to be serious enough, or if the history of offending indicates. However, the judiciary has proven reluctant to impose such discretionary sentences, with only $2 \%$ of those eligible receiving them.

Section 2 of the Crime (Sentences) Act 1997 provides automatic life sentences for those convicted of a second serious offence. This act also made provision for the courts to impose a prison sentence and at the same time order the immediate transfer of the defendant to hospital (a 'hospital direction'). The Criminal Justice Act 1991 allows for sentences that are longer than usual where issues of public protection arise. Thus, a variety of legislative vehicles are already available to detain those thought to pose an ongoing risk on an indefinite basis.

The White Paper Justice For All (Home Office, 2002) proposed indeterminate sentences for those who commit violent and sexual offences, which at present do not attract a life sentence, but are deemed to be 'dangerous', stating 'such offenders should remain in custody until their risks are considered manageable in the community'. A parole board would consider release after the minimum tariff had been served.

The MacLean Committee in Scotland was established in order to consider the sentencing and management of serious sexual and violent offenders. This committee suggested that there should be an order of lifelong restriction for those (both with and without mental illness) likely to pose an ongoing risk to the public and that there should be a mandatory assessment of risk and a new body to oversee this process (the Risk Management Authority). An order of lifelong restriction would ensure that once the prisoner had served the tariff, release would only be granted if it were thought that the risk of further offending had been reduced to acceptable levels. Such release on licence would be terminated if there were any concern regarding risk (Darjee \& Crichton, 2002). These suggestions have been incorporated into the Mental Health (Care and Treatment) (Scotland) Bill, which is awaiting Royal assent.

Coid \& Maden (2003) have recently argued that England and Wales should develop 'a coherent strategy for high-risk individuals led by the criminal justice system, with psychiatry in a secondary supporting role', similar to that proposed for Scotland. The Fallon Report suggested the creation of reviewable sentences for convicted prisoners with personality disorder (Fallon et al, 1999). A recent survey showed that this was supported by $63.4 \%$ of forensic psychiatrists (Shooter \& Cox, 1999). Such reviewable sentences would not require psychiatrists to sanction the extension of imprisonment.

\section{Lessons from abroad}

The Dutch terbeschikkingstelling (TBS; 'to dispose of') service was designed to protect the public from recidivists who suffer from 'defective development or pathological disorder of mental faculties', which include personality disorders (over 50\%) and 
Table 2 Comparison of orders used abroad

$\begin{array}{ll}\text { Country } & \text { Order } \\ \text { Holland } & \text { TBS } \\ \text { Scotland } & \text { Order of Life Long Restriction } \\ \text { South Africa } & \text { Dangerous Offender Direction } \\ \text { Canada } & \text { Dangerous Offender Order } \\ \text { USA } & \text { Civil Commitment of sex offenders }\end{array}$

$\begin{array}{ll}\text { Venue } & \text { Treatment } \\ \text { Prison and hospital } & \text { Yes } \\ \text { Prison } & \text { No } \\ \text { Prison } & \text { No } \\ \text { Prison } & \text { No } \\ \text { Prison } & \text { Yes }\end{array}$

psychosis (27\%) (McInerny, 2000) (Table 2). Within the health service TBS runs in parallel to the forensic psychiatry service, which deals primarily with organic and functional psychiatric disorders. TBS orders are usually imposed in combination with a prison sentence, not unlike hospital directions. They are of an indefinite duration although on average patients spend about 4 years in the programme. The assessment and treatment components of the service are separate. Unfortunately, there are no outcome studies of the TBS service available.

In the USA, 16 states have drafted sexual predator law, which prevents the release of inmates who are about to complete their criminal sentence but are deemed to be at high risk of reoffending on release. Very few patients have as yet been released from these programmes and consequently, the demand for more places is growing. It has been argued that the money being spent on building prisons could be better spent on providing sex offender treatment programmes in existing prisons.

Thirty-eight US states use the death penalty for those convicted of first-degree murder. The prosecution can submit evidence in the form of actuarial risk assessments to demonstrate the likelihood of reoffending to the presiding judge. Detainees deemed to be 'insane' are protected under the US Constitution and are transferred to hospital for treatment, to be returned for execution if they recover.

In Canada, any offender guilty of a violent or sexual offence, which receives a tariff of greater than 10 years and is thought to have a greater than $50 \%$ risk of reoffending receives a dangerous offender order. This is an indeterminate prison sentence, and few of those on this order have been released. South Africa has a similar approach.

\section{Treatment models available in the UK}

\section{The Henderson hospital}

Therapeutic communities such as that at the Henderson hospital in Surrey offer the best evidence for successful treatment of personality disorders (Dolan \& Coid, 1993). There is evidence that treatment there significantly reduces the treatment

burden placed on the health services after discharge (Dolan et al, 1996; Dolan \& Norton, 1997). Important features of the regime at the Henderson hospital (Norton, 1992), which is run as a therapeutic community, include:

- the voluntary nature of the programme;

- the sanction of discharge if the patient does not engage;

- a clear hierarchy and set of roles, which promote responsibility for one's own actions and an understanding of the actions of others;

- a limited period of treatment, which ensures good throughput and prevents therapeutic stagnation.

\section{The Personality Disorder Unit at Arnold Lodge}

The Personality Disorder Unit is a 10-bed unit situated on the same site as Arnold Lodge, a regional secure unit in Leicester. It offers a 2-year programme to sentenced prisoners with personality disorder predominantly under section 47 of the Mental Health Act 1983. All the patients are volunteers and if they do not engage, they are sent back to prison. The service attempts to reduce risk by treating the personality disorder. After the initial assessment period, a treatment formulation is produced that attempts to link aspects of the individual's personality with the offending. This serves as the basis of the treatment programme. Treatment is then targeted at areas of deficit. New skills such as anger management, problem-solving and controlling substance misuse are introduced in sessions and consolidated in the ward milieu.

\section{The Government's response: reforming the Mental Health Act}

The White Paper Reforming the Mental Health Act broadened the definition of mental disorder to 'any disability or disorder of mind or brain, whether permanent or temporary, which results in an impairment or disturbance of mental functioning.' (Department of Health, 2000) It also stated that 


\section{Box 3 Options proposed for managing individuals categorised as DSPD}

\section{Option A}

Amendment to criminal justice legislation to allow for the greater use of discretionary life sentences Amendment to the Mental Health Act 1983 to remove the 'treatability criterion' for civil detainees Services continue to be provided in specialist facilities in both prisons and secure mental health services

Option B

New powers in civil and criminal proceedings for the indeterminate detention of DSPD individuals (including powers for supervision and recall following detention)

Individuals held in a new service separately managed from the mainstream prison and health services - the 'third service'

'those who pose a significant risk of serious harm to others as a result of their mental disorder [are] to be detained in a therapeutic environment where they can be offered care and treatment to manage their behaviour'.

This White Paper defined the DSPD group as those who show a significant personality disorder, present a significant risk of causing serious physical or psychological harm from which the victim would find it difficult or impossible to recover (e.g. homicide, rape, arson) and in whom the risk presented appears to be functionally linked to the personality disorder.

\section{The Draft Mental Health Bill}

The Draft Mental Health Bill, published in June 2002, did not directly address the DSPD issue, leaving the accompanying consultation document to comment that those with personality disorders will be treated in exactly the same way as patients with other mental disorders (Department of Health, 2002). The Draft Mental Health Bill has a virtually identical definition of mental disorder as the White Paper (omitting the phrase 'whether permanent or temporary'). The draft bill is worded in such a way as to oblige the authorities to detain an individual 'who is [such] a substantial risk of causing serious harm to other persons, that it is necessary for the protection of those persons that medical treatment be provided to him'. For this especially high-risk group there is no option to treat the patient informally. There is no mention of therapeutic benefit or the patient's best interests, which had been included in the previous White Paper.

Like the preceding White Paper the Draft Mental Health Bill lacks the sexual deviation and substance misuse exclusions from the mental disorder category, and would thus facilitate the detention of paedophiles. It does not go so far as to advocate powers to manage behaviours arising from mental disorder although it has been argued that a broad definition of 'medical treatment' may well include this (Birmingham, 2002).
Sugarman (2002) has interpreted the change to the phrase 'medical treatment' from 'treatment in hospital' to preclude preventive detention on the grounds that it cannot be argued to be a treatment, since it provides no benefit to the individual concerned. One of the conditions of detention in the Draft Mental Health Bill is that appropriate medical treatment is available. Both these features may be cited as reasons not to engage a patient in much the same way as the treatability clause of the Mental Health Act 1983 is at present.

\section{DSPD services}

The consultation paper Managing Dangerous People with Severe Personality Disorder (Department of Health \& Home Office, 1999) proposed two options for the development of DSPD services (see Box 3). After a period of consultation the majority of interested parties preferred option B. The Government set aside $£ 126$ million for a 3-year programme (20002003) of development of specialist services for DSPD (Department of Health, 2000). The original proposals were for 320 new places in prisons and the NHS, and 75 'step-down' hostel places.

By October 2002, 36 assessment beds and 56 intervention beds were available at Whitemoor prison. Beds at Frankland prison and Rampton hospital are scheduled to be available from late 2003 and those at Broadmoor hospital by the end of 2005 (Table 3). There are discussions regarding the hostel places, but as yet no firm announcement has been made. Whitemoor prison is to be an independently evaluated pilot project of DSPD assessment. Studies

\section{Table 3 Government proposals for male DSPD bed}

$\begin{array}{lc}\text { Institution } & \text { Beds } \\ \text { Whitemoor prison } & 92 \\ \text { Frankland prison }^{1} & 80 \\ \text { Rampton hospital } & 70 \\ \text { Broadmoor hospital } & 70\end{array}$

1. This will take the most disruptive. 
regarding the interrater reliability of the assessment tools are being undertaken. At present, the assessment programme is 16 weeks long but is anticipated to be streamlined and shortened.

\section{Research and DSPD}

The Government has listed the following research aims related to the DSPD programme (Home Office, 1998):

- to estimate the number of people who would meet the criteria for DSPD;

- to evaluate the link between personality disorder and offending;

- to determine the validity of DSPD assessment tools;

- to evaluate the effectiveness of the treatment interventions.

The DSPD programme has already commissioned a variety of research projects to study the above and also aetiological factors and early intervention in antisocial personality disorder. This programme is to be scrutinised by a new body, the Expert Advisory Group. Research into the efficacy of treatment will be hampered by the small sample sizes and the long follow-up periods required.

\section{The personality disorder strategy document}

Recent government guidelines for personality disorder services have suggested the creation of multi-disciplinary teams. These teams are to be daypatient-based, led by psychologists or psychotherapists and are to target those with significant distress due to their personality disorder (National Institute for Mental Health in England \& Department of Health, 2003). Within the forensic service, there is to be the development of expertise to identify, assess and provide effective liaison with 'multi-agency protection panels') and the development of a small number of regional services for those with personality disorder at a higher level of security. It is proposed that these regional forensic services would receive those who had completed programmes in the DSPD service and also take some of individuals who were deemed to be sub-threshold for the DSPD services. It remains to be seen how the workload of assessing possible entrants into these regional units and the DSPD programme itself is divided between the general adult services and the forensic service.

\section{Pilot schemes}

\section{Assessment}

The Royal College of Psychiatrists' (1999) report Offenders with Personality Disorder recommended that assessment of personality disorder in offenders should include a DSM-IV or ICD-10 categorisation, a rating such as the PCL-R (Hare, 1991) or Minnesota Multiphasic Personality Inventory (Dahlstrom et al, 1975) and a structured clinical interview to provide psychodynamic information. It is likely that the pilot centres will accept those with at least one other DSM-IV personality disorder, apart from antisocial disorder, who also have a Psychopathy Check list (PCL-R) score of 30 or more. (Those who fulfil the criteria for psychopathy invariably also fulfil the criteria for antisocial personality disorder.)

The Prisoner Cohort Study (led by Professor Jeremy Coid) has been set up to assess a battery of tools that could be used to rate personality disorder (Table 4). A useful discussion of these tools can be found in Dolan \& Doyle (2000). The Historical/Clinical/Risk Management 20-item scale (HCR-20) is an example of structured clinical judgement, i.e. it is standardised with reference points to populations. The HCR-20 comprises 10 historical, 5 clinical and 5 risk items that have been shown to have good interrater reliability and to be predictive of future violence (Webster et al, 1997). Both the PCL-R and the HCR-20 are being assessed in a retrospective study of discretionary lifers to establish if they are able to predict violent recidivism.

\section{Assessment tools}

Tools will be required for both the initial assessment and to track progress during treatment. As yet, there

\section{Table 4 Examples tools for the assessment of personality disorder in offenders}

\section{Tool}

Psychopathy Checklist - Revised (PCL-R)

Psychopathy Checklist - Screening Version (PCL-SV)

Minnesota Multiphasic Personality Inventory (MMPI) ${ }^{1}$

Violence Risk Appraisal Guide (VRAG)

Historical/Clinical/Risk Management 20-item scale (HCR-20)

Sexual Violence Risk (SVR 20)

Static 99

\section{Reference}

Hare (1991)

Hart et al (1995)

Dahlstrom et al (1975)

Harris et al (1993)

Webster et al (1997)

Boer et al (1997)

Hanson \& Thornton (2000)

1. Not included in the Prisoner Cohort Study. 
are no proven tools to monitor reduction of risk during such a treatment programme, although the Broadmoor pilot scheme is to trial the Violence Risk Scale (Wong \& Gordon, 2001), which incorporates 6 static and 20 dynamic risk factors. This is an important consideration, since the proposed legislation states that those detained in DSPD services will only be released once their risk to the public has been reduced to an acceptable level.

\section{Treatment}

Initial priorities for the multi-disciplinary team will be engagement and motivational work; subsequent key areas include interpersonal skills and offencerelated work.

The Rampton DSPD pilot project will be working with a dialectical behaviour therapy model (Palmer, 2002). The existing Rampton personality disorder service mainly caters for men with borderline personality disorder and already uses dialectical behaviour therapy. The model involves a mixture of motivational work and attempts to equip the patients with new skills in their areas of deficit. One crucial difference between the patients in this programme and the DSPD group is that they must have shown recognition that they have a problem and show interest in treatment.

The Broadmoor pilot is to use a cognitivebehavioural approach with sex offenders and there is to be a research project investigating the efficacy of anti-androgen therapy in this group. Both the Whitemoor and Frankland pilots will be cognitivebehavioural in approach for those who have committed violent offences.

\section{Possible problems with the DSPD concept and services}

\section{No proven link between severity of personality disorder and dangerousness}

In his original statement, Jack Straw stated that those identified as 'dangerous and severely personality disordered' should not be written off as untreatable and that they 'must have the best possible chance of becoming safe, so as to be returned to the community, whenever that is possible' (Straw, 1999). This is reiterated in the White Paper, where it is implied that there is a link between the severity of personality disorder and the dangerousness of the individual. There is no clear evidence to make this link.

The Royal College of Psychiatrists has commented that the increasing use of the term severe personality disorder in the context of offenders reflects a growing reluctance to use the term psychopathy
(Royal College of Psychiatrists, 1999). This use of the phrase 'severe personality disorder' differs markedly from its original definition (Tyrer et al, 1994). Neither DSM-IV nor ICD-10 has any way of recording the severity of a personality disorder. Coid \& Maden (2003) have recently commented that 'personality disorder' is merely a euphemism for psychopathy.

The trend to provide psychological explanations for society's problems has resulted in demands to ascribe more and more behavioural disturbance to mental disorder. The use of medical diagnoses such as personality disorder in this way may be unhelpful as it encourages abdication of responsibility.

The Government's use of the acronym DSPD has subtly changed since the publication of the Draft Mental Health Bill. No longer is it used to describe a group of patients, rather it is the title of a programme for those whose severe personality disorder is illserved by currently available services.

\section{Dangerousness is an outmoded concept}

Dangerousness best describes the action rather than the individual and is transient and dependent on circumstance. As a concept it has been superseded by assessment of risk. Psychiatrists are unable to control many of the factors that influence dangerousness. Furthermore, there is little evidence that treatment of a personality disorder, if possible, would reduce the level of dangerousness.

\section{The problem of prediction}

There is an unrealistic expectation that psychiatrists are able to predict violent and sexual crime in those they assess and that they are therefore able to protect society. Buchanan \& Lesse (2001) reviewed all journal articles since 1970 that gave estimates for the sensitivity and specificity of tools used to measure 'dangerousness'. Sensitivity is defined as the proportion of actual offences predicted as offences by a test. Specificity is defined as the proportion of true negatives predicted by the test as negatives. In the 21 studies available, the mean sensitivity was 0.52 and the mean specificity was 0.68 . Using government figures, they calculated that the base rate of violence of those detained in special hospital or prison and fulfilling the criteria for DSPD was $9.5 \%$ in the first year (had they been in the community). Using these figures, they calculated that in order to successfully prevent one of those deemed to fulfil the criteria for DSPD from offending in a 1-year period, five others, who would not have offended, would have to be detained. They described this as the number needed to detain (NND) in order to prevent one offence (in this case six). 


\section{Engagement with DSPD services}

By their very nature, individuals in the DSPD group will prove difficult to engage in treatment. For those detained by the DSPD services, the prospect of indeterminate incarceration may lead to even less cooperation with the system, a downward spiral of bad behaviour and an adverse effect on the therapeutic milieu. A core feature of the successful treatment of DSPD individuals at the Henderson hospital is empowerment of individuals to take responsibility for their own actions. A restrictive environment is unlikely to be conducive to such an approach. Personality disorder treatment programmes such as those of the Henderson hospital and Arnold Lodge have thus far focused on those who have opted into treatment rather than those who have had it forced upon them.

\section{The legal dilemma}

The Government has claimed that the DSPD proposals are fully compliant with the Human Rights Act 1998. The proposed legislation would allow the detention of an unconvicted individual with personality disorder if there were significant risk of future serious offending. Some have seen the detention of the unconvicted as a serious breach of the individual's rights under Article 5 of the Human Rights Act (prohibition of unlawful detention) (Gunn \& Holland, 2003). Others have countered that only those with 'evidence of incidents which could have led to convictions' would be dealt with in this way (Otten, 2003). Birmingham (2002), in his commentary on the Draft Mental Health Bill, noted that the drive to detain within the DSPD service on the basis of 'unsound mind' (Article 5) is now losing favour. The rights of the detainee under Article 5 (right to liberty and security) and Article 8 (right to respect of private and family life) must be weighed against the rights of the public under Article 2 (the right to life).

\section{Ethical problems}

Detention in the DSPD service will carry with it a heavy burden of stigma, which will run counter to Standard 1 of the National Service Framework, that 'health and social services should combat discrimination against individuals and groups with mental health problems and promote their social inclusion' (Department of Health, 1999).

The detention of an individual solely for public protection also lacks reciprocity: the detainee has a right to some benefit in exchange for the loss of his freedom. Furthermore, the obligation to share information with other services and thus reduce patient confidentiality may discourage patients from presenting themselves to psychiatrists. Perversely, the very measures designed to reduce the risks to the public may alienate the target group, make monitoring more difficult and ultimately leading to increased risk.

\section{Impact of DSPD legislation on general psychiatry services}

The creation of services to detain individuals with personality disorder who are deemed to be a risk to the public is likely to have an impact on general adult psychiatry services. Those who have undergone an assessment for the DSPD service (within the forensic service as set out by the recent government guidelines on personality disorder services) and have been found to be sub-threshold for both the DSPD and the proposed regional personality disorder services are likely to return to a general psychiatry ward. There are concerns that the added workload for the general services would not be matched by increased funding. Staff from the already stretched existing services may well be enticed away to the new well-resourced services. Such significant investment to reduce the risk of violence might be better spent on targeting those who misuse substances with and without comorbid psychiatric disorder. In its defence, the DSPD programme claims that it will be a specialist service dealing with a t most a few hundred patients and not having any knock-on effect on the workload of the adult services.

\section{Conclusions}

The Government is concerned that there is a small group of dangerous individuals with personality disorders who are responsible for a disproportionate amount of violent and sexual crime. A White Paper set out proposals for a DSPD service to detain and treat this group, who are defined as having a personality disorder that is functionally linked to a significant risk of harm. This is not the first attempt to categorise high-risk individuals using their antisocial behaviour and their inherent constitution. Other countries have chosen to deal with such individuals within the penal rather than the health system. Four DSPD units are being set up and various models of treatment investigated. The White Paper and the Draft Mental Health Bill have attracted much criticism. Specific concerns regarding the DSPD proposals include: the lack of evidence of a link between dangerousness and personality disorder, problems related to identifying 
this group accurately, the likelihood of poor cooperation with treatment if treatment is obligatory, possible breeches of the Human Rights Act, stigma and finally the knock-on effects on the general adult services.

\section{References}

American Psychiatric Association (1994) Diagnostic and Statistical Manual of Mental Disorders (4th edn) (DSM-IV). Washington, DC: APA.

Birmingham, L. (2002) Detaining dangerous people with mental disorders. New framework is open for consultation. $B M J, 325,2-3$.

Boer, D., Hart, S., Kropp, P., et al (1997) Manual for the Sexual Violence Risk - 20: Professional Guidelines for Assessing Risk of Sexual Violence. Vancouver, BC: British Columbia Institute on Family Violence.

Buchanan, A. \& Lesse, M. (2001) Detention of people with severe personality disorders: a systematic review. Lancet, $358,1955-1959$

Cleckley, H. (1941) The Mask of Sanity. St Louis, MO: CV Mosby.

Coid, J. \& Maden, T. (2003) Should psychiatrists protect the public? BMJ, 326, 406-407.

Dahlstrom, W., Welsh, G. \& Dahlstrom, L. (1975) An MMPI Handbook. Volume 2. Minneapolis, MN: University of Minnesota Press.

Darjee, R. \& Crichton, J. (2002) The MacLean Committee: Scotland's answer to the 'dangerous people with severe personality disorder' proposals? Psychiatric Bulletin, 26, $6-8$.

Department of Health (1999) National Service Framework for Mental Health: Modernising Standards and Service Models. London: Stationery Office.

- (2000) Reforming the Mental Health Act. London: Stationery Office.

- (2002) The Draft Mental Health Bill. London: Stationery Office.

Department of Health \& Home Office (1994) Report of the Department of Health and Home Office Working Group on Psychopathic Disorder. London: Department of Health

- (1999) Managing Dangerous People with Severe Personality Disorder. Proposals for Policy Development. London: Home Office.

Dolan, B. \& Coid, J. (1993) Psychopathic and Antisocial Personality Disorders. Treatment and Research Issues. London: Gaskell.

— \& Norton, K. (1997) Change in borderline symptoms one year after therapeutic community treatment for severe personality disorder. British Journal of Psychiatry, 171, 274279.

— \& Doyle, M. (2000) Violence risk prediction. Clinical and actuarial measures and the role of the Psychopathy Checklist. British Journal of Psychiatry, 177, 303-311.

-, Warren, F., Menzes, D., et al (1996) Cost-offset following specialist treatment of severe personality disorder. Psychiatric Bulletin, 20, 413-417.

Fallon, P., Burglass, R., Edwards, B., et al (1999) Report of the Committee of Inquiry into the Personality Disorder Unit, Ashworth Special Hospital (2 vols and Executive Summary) (Cm. 4194 I and II). London: Stationery Office.

Farnham, F. \& James, D. (2001) Dangerousness and dangerous law. Lancet, 358, 1926.

Gunn, J. (2000) Future directions for treatment in forensic psychiatry. British Journal of Psychiatry, 176, 332-338.

Gunn, M. \& Holland, T. (2003) Some thoughts on the proposed Mental Health Act. Journal of Mental Health Law, December 2002, 367

Hanson, R. \& Thornton, D. (2000) Static-99: Improving Risk Assessments for Sex Offenders: User Report 99-02. Ottawa: Department of the Solicitor General of Canada.
Hare, R. (1991) Manual for the Hare Psychopathy Checklist Revised. Toronto: Multi-Health Systems.

-, Cooke, D. \& Hart, S. (1999) Psychopathy and sadistic personality disorder. In Oxford Textbook of Psychopathology (eds T. Milton, P. Blaney, \& R. Davis). Oxford, Oxford University Press.

- Clark, D., Grann, M., et al (2000) Psychopathy and the predictive validity of the PCL-R: an international perspective. Behavioural Sciences and Law, 18, 623-645.

Harris, G., Rice, M. \& Quinsey, V. (1993) Violent recidivism of mentally disordered offenders: the development of a statistical prediction instrument. Criminal Justice and Behaviour, 20, 315-335.

Hart, S., Cox, D. \& Hare, R. (1995) The Hare Psychopathy Checklist-Revised Screening Version (PCL: SV). Toronto: MultiHealth Systems.

Home Office (1998) Criminal Statistics England and Wales 1997 (Cm 4162). London: Stationery Office.

- (2002) Justice For All. London: Stationery Office.

Lewis, A. (1974) Psychopathic personality: a most elusive category. Psychological Medicine, 23, 691-707.

Lewis, G. \& Appleby, L. (1988) Personality disorder: the patients psychiatrists dislike. British Journal of Psychiatry, 153, 44-49.

McInerny, T. (2000) Dutch TSB forensic services: a personal view. Criminal Behaviour and Mental Health, 10, 213-228.

National Institute for Mental Health in England \& Department of Health (2003) Personality Disorder: No Longer a Diagnosis of Exclusion. London: Department of Health.

Norton, K. (1992) Personality disordered individuals: the Henderson Hospital model of treatment. Criminal Behaviour and Mental Health, 2, 80-191.

Otten, G. (2003) The Draft Mental Health Bill 2002. Journal of Mental Health Law, December 2002, 389.

Palmer, R. (2002) Dialectical behaviour therapy for borderline personality disorder. Advances in Psychiatric Treatment, 8, $10-16$.

Prichard, J. (1835) A Treatise on Insanity, and Other Disorders Affecting the Mind. London: Gilbert and Piper.

Rice, M., Harris, G. \& Cormier, C. (1992) An evaluation of a maximum security community for psychopaths and other mentally disordered offenders. Law and Human Behaviour, 16, 399-412.

Robbins, L. (1966) Deviant Children Grown Up: A Sociological and Psychiatric Study of Sociopathic Personality. Baltimore, MD: Williams \& Wilkins.

Royal College of Psychiatrists' (1999) Offenders with Personality Disorder (Council Report CR71). London: Gaskell.

Rozenberg, J. (2001) Law chief in call to lock up child sex suspects. Daily Telegraph, 27 December.

Shooter, M. \& Cox, J. (1999) Royal College of Psychiatrists Response to 'Managing Dangerous People with Severe Personality Disorder: Proposals for Policy Development'. London: Royal College of Psychiatrists. http://www. rcpsych.ac.uk/college/parliament/responses/dspd.pdf

Singleton, N., Meltzer, H. \& Gatward R. (1998) Psychiatric Morbidity among Prisoners in England and Wales. London: Office for National Statistics.

Straw, J. (1999) Severe personality disorders. Hansard (UK Parliamentary Reports, House of Commons), 15 February, 601-613.

Sugarman, P. (2002) Detaining dangerous people with mental disorders. BMJ, 325, 659 .

Tyrer, P., Merson, S., Onyett, S., et al (1994) The effect of personality disorder on the clinical outcome, social networks and adjustment: a controlled trial of psychiatric emergencies. Psychological Medicine, 24, 731-740.

Webster, C., Douglas, K., Eaves, D., et al (1997) Assessing risk of violence to others. In Impulsivity: Theory, Assessment and Treatment (eds C. Webster \& M. Jackson). New York: Guildford Press.

Wong, S. \& Gordon, A. (2001) The Violence Risk Scale. Forensic Update, 67, October.

World Health Organization (1992). The ICD-10 Classification of Mental and Behavioural Disorders. Clinical Descriptions and Diagnostic Guidelines. Geneva: WHO. 


\section{Multiple choice questions}

1 Regarding the Psychopathy Checklist - Revised (PCL-R):

a it was originally developed in a non-forensic population

b it has an optional interview, but must include a notes review

c it was originally designed as a risk assessment tool

d scores over 30 are associated with better prognosis after treatment

e scores over 30 are associated with increased rates of recidivism

2 The following are features of psychopathy:

a polite obedience

b lack of guilt

c honesty

d empathy

e low self-esteem.

3 Regarding risk management and sentencing:

a only $2 \%$ of those eligible receive discretionary life sentences

b a hospital direction allows a court to pass a prison sentence and also to direct the defendent to hospital for treatment

c the Draft Mental Health Bill would not allow the civil detention of released prisoners deemed to continue to pose a risk to the public

d the Draft Mental Health Bill would allow the detention of individuals with personality disorders solely for the purposes of public protection

e the NND is an indication of how many individuals must be detained to prevent a single offence.
4 Regarding risk assessment:

a the HCR-20 is not a structured clinical assessment tool

$b$ the HCR-20 is a standardised tool

c when screening for rare conditions, false positives are more likely than false negatives

$\mathrm{d}$ the sensitivity of a risk assessment tool is defined as the proportion of actual offences predicted by the test as offences

e the specificity of a risk assessment tool is defined as the proportion of true negatives predicted by the test as negatives.

5 Regarding the DSPD proposals and the Human Rights Act 1998:

a DSPD detainees' rights may be breeched with regards to Articles 5 and 8

b Article 2 relates to the right to life

c Article 8 relates to the prohibition of torture and inhumane treatment

d Article 5 allows for the lawful detention of persons of unsound mind

e there is a balance between the rights of the detainee and the general public.

\section{MCQ answers}

\begin{tabular}{|c|c|c|c|}
\hline 1 & 2 & 3 & 4 \\
\hline a F & a F & a $\mathrm{T}$ & a F \\
\hline $\mathrm{b} T$ & b $\mathrm{T}$ & $\mathrm{b} T$ & b $\mathrm{T}$ \\
\hline c F & c F & c F & c $\mathrm{T}$ \\
\hline $\mathrm{F}$ & d F & d $\mathrm{T}$ & d $\mathrm{T}$ \\
\hline $\mathrm{T}$ & e $F$ & e $\mathrm{T}$ & e $\mathrm{T}$ \\
\hline
\end{tabular}

\section{Communicating with Vulnerable Children}

\section{A guide for practitioners \\ By David P.H. Jones}

This practical guide is intended for use by all practitioners who work with children and young people. It is about how best to communicate when the child has suffered adversity, whether experienced personally or as a witness. The focus is on helping children provide full and accurate accounts of their experiences without suggestion from adults. Each chapter sets out the relevant policy and procedural context and reviews the available evidence, then gives practical advice about how best to communicate with the child. The text includes a chapter on how to use the book and useful summary lists to photocopy for everyday use.

June 2003, paperback, 188pp, ISBN 190124291 9, Price $£ 18.00$

Available from: Book Sales, Royal College of Psychiatrists, 17 Belgrave Square, London SW1X 8PG, UK. Tel: +44 (0)20 72352351 ext 146. Fax: +44 (0)20 7245 1231. Online ordering at: www.rcpsych.ac.uk/publications 